\title{
Cirrhotic cardiomyopathy
}

\author{
Florence Wong
}

Received: 30 July 2008/ Accepted: 10 October 2008/Published online: 11 November 2008

(C) Asian Pacific Association for the Study of the Liver 2008

\begin{abstract}
Cirrhotic cardiomyopathy is a recently recognized condition in cirrhosis consisting of systolic incompetence under condition of stress, diastolic dysfunction related to altered diastolic relaxation, and electrophysiological abnormalities in the absence of any known cardiac disease. It can be diagnosed by using a combination of electrocardiograph, 2-dimensional echocardiography, and various serum markers such as brain natriuretic factor. The underlying pathogenetic mechanisms include abnormalities in the $\beta$-adrenergic signaling pathway, altered cardiomyocyte membrane fluidity, increased myocardial fibrosis, cardiomyocyte hypertrophy, and ion channel defects. Various compounds for which levels are elevated in cirrhosis such as nitric oxide and carbon monoxide can also exert a negative inotropic effect on the myocardium, whereas excess sodium and volume retention can lead to myocardial hypertrophy. Various toxins can also aggravate the ion channel defects, thereby widening the QRS complex causing prolonged QT intervals. Clinically, systolic incompetence is most evident when cirrhotic patients are placed under stress, whether physical or pharmacological, or when the extent of peripheral arterial vasodilatation demands an increased cardiac output as in the case of bacterial infections. Acute volume overload such as immediately after insertion of a transjugular intrahepatic portosystemic shunt or after liver transplantation can also tip these cirrhotic patients into cardiac failure. Treatment of cirrhotic cardiomyopathy is unsatisfactory. There is some evidence that $\beta$-blockade
\end{abstract}

F. Wong $(\bowtie)$

Department of Medicine, Toronto General Hospital, University

of Toronto, 9th floor, North Wing, Room 983, 200 Elizabeth

Street, Toronto, ON, Canada M5G 2C4

e-mail: florence.wong@utoronto.ca may help some cirrhotic patients with baseline prolonged QT interval. Long-term aldosterone antagonism may help reduce myocardial hypertrophy. Future studies should include further elucidation of pathogenetic mechanisms so as to develop effective treatment strategies.

Keywords Cirrhosis - Cardiomyopathy ·

Diastolic dysfunction · Systolic incompetence · QT interval

\section{Introduction}

Cardiomyopathy is derived from the Greek roots: cardio (heart), + mys (muscle) + pathos (disease), that is, it is a condition affecting the heart muscles. Cardiomyopathy is broadly divided into 3 basic types: dilated cardiomyopathy, in which the heart muscles become weak and the cardiac chambers subsequently dilate; hypertrophic cardiomyopathy, in which the heart muscles themselves are much thicker than normal; and restrictive cardiomyopathy, in which the heart becomes stiff and cannot fill efficiently during diastole. Any of these abnormalities can affect cardiac function, be it systolic function, diastolic function, or rhythm conduction.

Historically, liver cirrhosis has not been associated with any cardiac abnormalities, despite the fact that a hyperdynamic circulation has been described in patients with cirrhosis more than 50 years ago [1]. Cirrhotic patients were noted to have resting tachycardia, warm peripheries, a bounding pulse, and a wide pulse pressure, but these findings were attributed to the effects of alcohol on the circulation. Beginning in the late 1980s, occasional reports of unexpected deaths due to heart failure following liver transplantation [2], transjugular intrahepatic portosystemic stent shunt (TIPS) insertion [3], and surgical portocaval 
shunts [4] led to an upsurge of interest in investigating for cardiac dysfunction related to cirrhosis. There followed detailed studies assessing the cardiovascular complications of cirrhosis. Over the last 2 decades, there is accumulating evidence to suggest that the presence of cirrhosis per se is associated with significant cardiovascular abnormalities, irrespective of the cause of cirrhosis. These include resting increased cardiac output; decreased systemic vascular resistance [1]; reduced myocardial contractility or systolic incompetence, especially under conditions of stress, whether physiological [5], physical [6, 7], or pharmacological [8]; increased thickness of the left ventricle [9-11], associated with diastolic dysfunction; and electrophysiological abnormalities [12-14]. This constellation of abnormalities has been termed cirrhotic cardiomyopathy [15]. However, cirrhotic cardiomyopathy is not a well-recognized condition. It is often confused with alcoholic cardiomyopathy or alcoholic heart muscle disease. Even when the changes associated with cirrhotic cardiomyopathy are detected, the skeptics have often dismissed the presence of cirrhotic cardiomyopathy because overt cardiac failure is uncommon in cirrhosis. This review discusses the evidence supporting the presence of cirrhotic cardiomyopathy, the definition, possible pathogenetic mechanisms, clinical presentations, and potential treatments of cirrhotic cardiomyopathy.

\section{Evidence supporting the presence of cardiomyopathy in cirrhosis}

\section{Systolic dysfunction}

From the mid-1980s to the early 1990s, several investigators showed that cardiac contractile reserve is diminished in different rat models of nonalcoholic cirrhosis [16-19]. Notable is the landmark study of Caramelo and colleagues [17], who infused saline into rats with carbon tetrachlorideinduced cirrhosis. There was a 50\% decrease in cardiac output despite a $112 \%$ increase in peripheral vascular resistance [17]. This suggests that the decreased cardiac contractile response observed in cirrhosis was due to cirrhosis per se rather than related to the damaging effects of alcohol on the myocardium as it had been claimed up to then. Few years later, human studies in nonalcoholic cirrhosis showed similar results. Bernardi et al. [12] measured systolic time intervals that has been validated as a reliable method of assessing ventricular contractile performance [20] and found the ratio of pre-ejection period to left ventricular ejection time to be prolonged in 22 alcoholic and nonalcoholic cirrhotic patients both at rest and after exercise, an indication of contractile dysfunction. Grose et al. [21] reported a submaximal increase in cardiac output following exercise in both alcoholic and nonalcoholic cirrhotic patients compared with controls. This was due to the inability of these patients to mount a sufficient inotropic and chronotropic response despite a greater increase in the end-diastolic volume. Ejection fraction remained unchanged, contrary to an increase as predicted by Starling's law. Laffi et al. [5] assessed the isotropic and chronotropic response in a group of nonalcoholic cirrhotic patients and reported a significantly decreased stroke volume in response to active tilting, leading to a reduced cardiac index despite a significant increase in heart rate. Wong et al. [9] demonstrated in both alcoholic and nonalcoholic cirrhotic patients, with or without ascites, an abnormal and inverse systolic pressure to end-systolic volume relationship, an index of myocardial contractility [22]. With graded exercise test by using upright bicycle ergometry, both the absolute and the percentage increases in cardiac output in the cirrhotic patients were significantly decreased compared with the controls [6]. Furthermore, the contractile abnormality appeared to be more severe in the ascitic cirrhotic patients, suggesting a correlation between the degree of cardiac dysfunction and the severity of liver disease.

\section{Diastolic dysfunction}

Diastolic dysfunction, when present, is characterized by an abnormal pattern of transmitral flow and increased atrial contribution to the late ventricular filling, and best depicted by the reduced $\mathrm{E}$ wave to $\mathrm{A}$ wave ratio (Fig. 1). Other parameters of diastolic dysfunction include a prolonged isovolumic relaxation time and increased deceleration time (Fig. 1), which represent increased resistance to ventricular inflow. With 2-dimensional echocardiography, Pozzi et al. [10] found that in cirrhotic patients with tense ascites, the A wave velocity is markedly increased, the E/A ratio is markedly reduced, and the deceleration time is significantly prolonged. Removal of the ascitic fluid by rapid total paracentesis reduces the A wave velocity and increases the E/A ratio to values similar to those of cirrhotic patients without ascites but still abnormal as compared with healthy controls. Finucci et al. [11] reported increased stroke volume, left ventricular end-diastolic volume, left atrial volume, peak A velocity, deceleration time of $\mathrm{E}$ wave, and decreased E/A ratio (1.02 vs. 1.22) in 42 Child-Pugh class $\mathrm{B}$ and $\mathrm{C}$ cirrhotic patients, half of whom with alcoholic etiology. The prolonged deceleration time was unaffected by the presence of ascites. A subanalysis did not reveal any difference in transmitral diastolic filling variables between alcoholic or nonalcoholic patients, further corroborating previous reports that cirrhosis per se is responsible for cardiac abnormalities. Wong et al. [9] found an increased interventricular septal and posterior wall thickness, as well as increased diameter of the left atrium in a mixed 


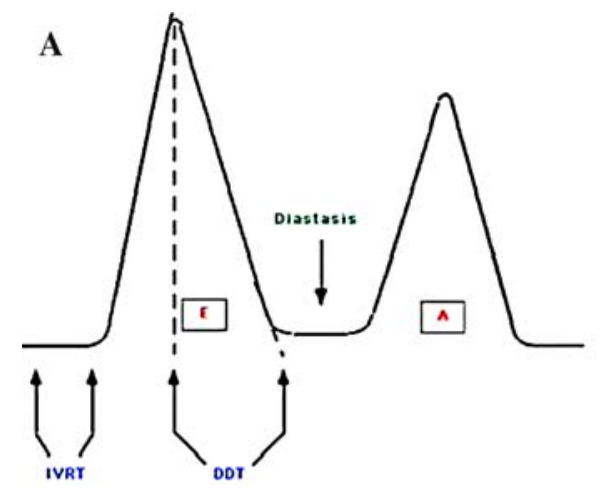

Fig. 1 a In normal individuals, during diastole, there is an initial phase of rapid transmitral flow as the mitral valve opens and the left ventricle relaxes. This early filling phase results in a peak in the transmitral flow profile known as the $\mathrm{E}$ wave. This is followed by a slow phase of filling called diastasis, during which time there is slowing of the left ventricular relaxation, associated with a rise on left ventricular diastolic pressure. A late phase of rapid filling occurs with atrial contraction, resulting in a second peak of transmitral flow profile known as A wave. b In patients with diastolic dysfunction,

population of 39 preascitic and ascitic patients. All patients also had some degree of diastolic dysfunction. At variance with the findings of Finucci et al. and in agreement with Pozzi et al., they found isovolumic relaxation time to be prolonged in cirrhotic patients irrespective of the presence of ascites, with significantly reduced E/A ratio only in ascitic subjects. Accordingly, they concluded that ascitic patients had a thicker left ventricular wall and a lower E/A ratio, indicating a greater impedance to venous return than preascitic cirrhotic patients.

\section{Electrophysiological abnormalities}

Several electrophysiological abnormalities have been observed in cirrhosis and these include chronotropic incompetence, electromechanical uncoupling, and prolonged QT interval.

Chronotropic incompetence is the failure of the heart rate to respond to physiological and pharmacological stimuli. Sympathetic activation by various means, such as Valsalva maneuver, ice-cold skin stimulation, mental stress, tilting, and isometric and isotonic physical exercise, does not evoke an adequate acceleration of heart rate despite a higher than normal increase in plasma norepinephrine concentrations [23, 24]. Such a defect is exhibited by both alcoholic and nonalcoholic patients and is proportional to the severity of cirrhosis.

The time between the onset of electrical systole and mechanical systole is normally tightly controlled, and it is referred to as electromechanical coupling. Defect in electromechanical coupling leads to the asynchrony between electrical and mechanical systoles. The previously
B

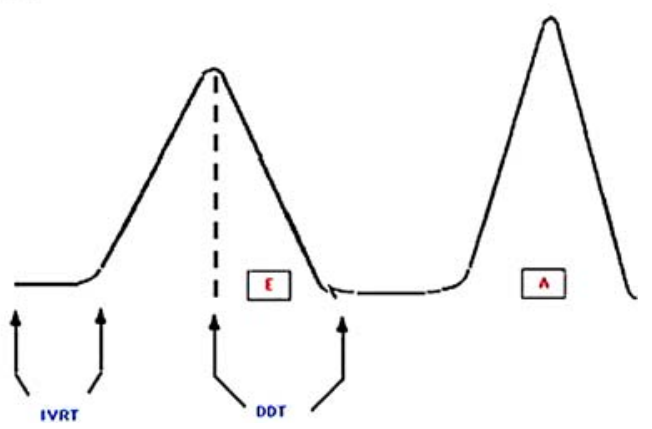

there is impedance to diastolic inflow, resulting in a smaller $\mathrm{E}$ wave. The atrial contraction contributes to a greater portion of the left ventricular filling and hence a higher A wave. Abbreviations: IVRT, isovolumic relaxation time, which is the time period during which the mitral and aortic valves are both closed. The left ventricle begins to relax, but before left ventricular filling occurs; DDT, diastolic deceleration time, which is the time period from the peak of the early diastolic filling velocity to the end of the $\mathrm{E}$ wave

mentioned study by Bernardi et al. [7] evaluating cardiac function in cirrhosis under rest and after isometric exercise showed that there was prolongation of the pre-ejection period at rest, together with defective shortening after exercise, suggesting that it was a defect in electromechanical coupling that was responsible for the contractile dysfunction in these patients. Henriksen and colleagues [25] reported that the difference between the electrical and mechanical systolic times was substantially longer in cirrhotic patients with prolonged QT intervals than those with normal QT intervals. However, the aortic pressure curves evaluated by catheterization showed that the duration of the mechanical systole in patients with prolonged QT interval was not altered, but its relationship with the duration of the electrical systole was abnormal, confirming dys-synchrony in the coupling between the electrical and mechanical systoles in these patients.

QT interval prolongation frequently occurs in cirrhotic patients, irrespective of the etiology of the disease. Its prevalence is about $45 \%$, which is strikingly higher than the $5 \%$ prevalence in the general population, and is broadly proportional to the severity of cirrhosis, rising from $25 \%$ in class A to $51 \%$ in class B and up to $60 \%$ or more in class C of Child-Pugh classification [12]. The presence of prolonged QT interval provides the substrate for ventricular arrhythmias and therefore may be responsible for the sudden deaths observed following stressful procedures such as TIPS insertion or liver transplantation. The recent finding that QT interval prolongation is correlated with brain natriuretic peptide (BNP) (see the subsequent text), the gene of which is predominantly expressed in myocytes of failing left ventricles, points to the presence of a 
cardiomyopathy as the cause of this electrophysiological abnormality [26].

\section{Serum markers}

Brain natriuretic peptide, a sensitive and useful marker for early stage heart disease, has been found to be elevated in some preascitic but most of ascitic cirrhotic patients [27-29]. Henriksen and colleagues [26] found that both pro-BNP (a propeptide of BNP) and BNP elevations correlated with the severity of cirrhosis as well as the degree of cardiac dysfunction. Yildiz et al. [30] also reported a significant correlation between the BNP levels and the Child-Pugh score. Furthermore, the level of BNP was proportional to the interventricular septal wall thickness and left ventricular wall thickness [30]. Elevated circulating levels of cardiac troponin 1, a specific marker of myocardial injury [31], have also been reported in cirrhosis without other causes of cardiac disease [32]. Similar elevated levels of adrenomedullin, a hormone involved in the regulation of vascular tone and natriuresis [33] as well as influencing myocardial inotropy [34, 35], have been found in cirrhosis without clinical heart disease [36, 37] as in patients with heart failure [38, 39] and ventricular hypertrophy [40]. Adrenomedullin mediates its effects through its second messenger, cyclic adenosine mono-phosphate (cAMP), which, in turn, increases the production of nitric oxide (NO) [41]. Its role in cardiac failure is mostly to reduce the afterload and dilate the coronary vessels via its vasodilatory actions [42], but the exact role of adrenomedullin in causing cardiac dysfunction in cirrhosis is unclear. It is postulated that adrenomedullin may contribute to myocardial dysfunction in cirrhosis via the negative inotropic effect of NO (see the subsequent text). In keeping with the fact that cirrhotic cardiomyopathy is more severe in the more advanced stage of cirrhosis, the levels of these markers of cardiac dysfunction are generally higher in ascitic than nonascitic cirrhotic patients.

\section{Definition of cirrhotic cardiomyopathy}

In 2005, a working party of expert hepatologists and cardiologists met at the World Congress of Gastroenterology and proposed a working definition of cirrhotic cardiomyopathy [43]. Such a definition is needed so that the condition can be properly diagnosed, and investigators have a uniform set of guidelines to formulate their hypotheses, from whence treatment options can be developed. The working definition proposes that "cirrhotic cardiomyopathy is a form of chronic cardiac dysfunction in patients with cirrhosis, characterized by blunted contractile responsiveness to stress, and/or altered diastolic relaxation with electrophysiological abnormalities in the absence of other known cardiac disease." Currently, it is proposed that cirrhotic cardiomyopathy can be diagnosed if evidence of either systolic or diastolic dysfunction, together with supporting criteria such as electrophysiological abnormalities or abnormal serum markers, is present [43]. The exact maneuvers that can bring forth systolic dysfunction have not yet been standardized. However, objective measurements of diastolic dysfunction are easily obtainable, as are other electrocardiograph and 2-dimensional echocardiography parameters and serum markers. It is the aim of the Cirrhotic Cardiomyopathy Working Party to set guidelines for the diagnosis of cirrhotic cardiomyopathy in the near future.

\section{Pathogenetic mechanisms underlying cirrhotic cardiomyopathy}

Systolic dysfunction

Cardiomyocyte contractility is mainly regulated by $\beta$-adrenergic stimulation. The binding of either adrenaline or noradrenaline on to the $\beta$-adrenergic receptor leads to the interaction of the receptor with a binding protein known as the Gs or the stimulatory protein. This, in turn, leads to the activation of another membrane-bound protein known as adenylate cyclase. The net result is the production of cAMP from adenosine triphosphate (ATP). The Gs protein also promotes the direct activation of the calcium channel of the sarcolemma. Cyclic AMP plays a crucial role in activating protein kinases; one of these is protein kinase $\mathrm{A}$, which phosphorylates several proteins including the calcium release receptor located within the sarcoplasmic reticulum. This promotes the influx of calcium into the cytosol of the cardiomyocyte, causing actin-myosin myofibrillar cross-linking, which results in cellular contraction (Fig. 2) [44].

In experimental cirrhosis, several abnormalities in the $\beta$-adrenergic signaling pathway have been identified. For example, there is a decrease in $\beta$-adrenergic receptor density, a reduction in Gs proteins, and attenuation of adenylate cyclase activity with resultant decreased cAMP generation [45], all of which negatively affect cardiomyocyte contractility. In addition, there have been reports of altered membrane fluidity due to changes in the lipid composition of the cardiomyocyte plasma membrane [46, 47], thus hindering the function of the receptors embedded in the membrane such as the $\beta$-adrenergic receptor.

There are also other inhibitory pathways that contribute to the decreased contractility of the cardiomyocyte and hence decreased systolic function in cirrhosis. The cannabinoid signaling system is usually minimally expressed 
Fig. 2 Major stimulatory and inhibitory influences on cardiomyocyte contraction in cirrhosis. Abbreviations: AC, adenylate cyclase; ATP, adenosine triphosphate; $\beta$-AP, $\beta$-adrenergic receptor; $\mathrm{Ca}^{2+}$, calcium ion; CaRR, calcium release receptor; cAMP, cyclic adenosine monophosphate; CB-1R, cannabinoid receptor-1; cGMP, cyclic guanosine monophosphate; $\mathrm{CO}$, carbon monoxide; NO, nitric oxide; NOS, nitric oxide synthase; PKA, protein kinase A; PKG, protein kinase G; SR, sarcoplasmic reticulum; TNF- $\alpha$, tumor necrosis factor- $\alpha$

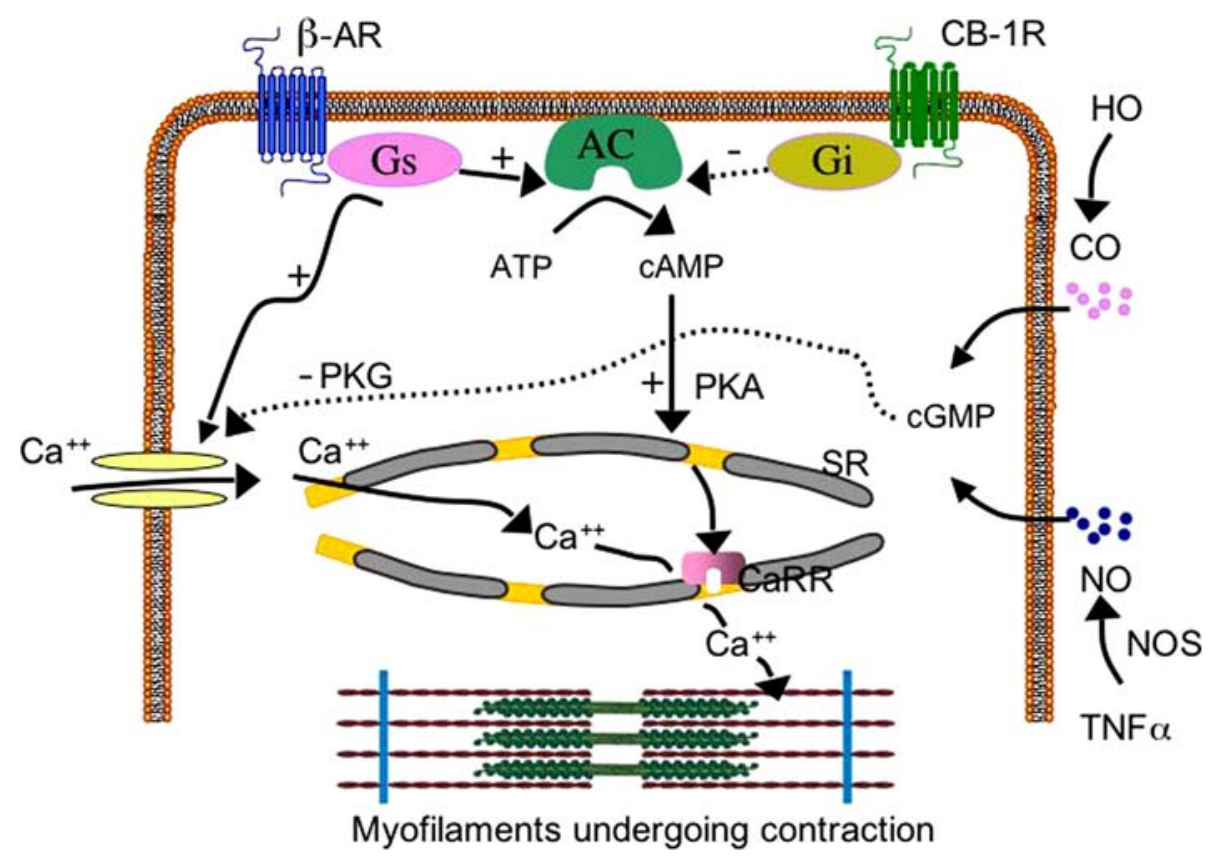

in healthy individuals. However, in chronic liver disease, there is significant upregulation of the cannabinoid signaling pathway [48]. In the cardiomyocyte, cannabinoid subtype-1 (CB-1) receptors are known to exert a negative inotropic effect via activation of the inhibitory G (Gi) protein. The Gi protein inhibits adenylate cyclase activity, reducing the production of cAMP with resultant decreased calcium influx into the cytosol of the cardiomyocyte (Fig. 2). Gaskari et al. [49] reported that cardiac papillary muscles isolated from rats with cirrhosis induced by bile duct ligation showed a blunted contractile response to isoproterenol, and that this was restored by the administration of the CB-1 receptor antagonist AM 251 [49]. In another study in rats with carbon tetrachloride-induced cirrhosis, activation of the CB-1 receptors resulted in inhibition of $\beta$-adrenergic responsiveness, and treatment with the CB-1 receptor antagonist AM 251 improved contractile function [50].

The NO and carbon monoxide (CO) pathways also have a negative effect on cardiomyocyte contraction. Both NO and $\mathrm{CO}$ are evanescent gases produced in the cirrhotic heart by increased inducible NO synthase and hemoxygenase activities, respectively. Both gases stimulate guanylate cyclase to produce cyclic guanosine monophosphate (cGMP), which phosphorylates protein kinase $\mathrm{G}$ to inhibit calcium influx into the cytosol of the cardiomyocyte (Fig. 2). Stimulation of the NO pathway is possibly related to increased cytokines in cirrhosis, as significantly increased tumor necrosis factor- $\alpha$ (TNF- $\alpha$ ) and cGMP contents have been reported in bile duct ligation model of cirrhotic rats [51]. In another study using the same model of cirrhotic rats, heme-oxygenase mRNA transcription and protein expression were significantly augmented in cirrhotic hearts compared with sham-operated controls. Treatment with zinc protoporphyrin, an inhibitor of hemooxygenase, significantly decreased cGMP production and improved the blunted papillary muscle contractility, whereas it had no effect on control muscles [52]. Together, these findings support the role of $\mathrm{NO}$ and $\mathrm{CO}$ in mediating the reduced contractile response in cirrhosis.

More recently, a novel mechanism of reduced myocardial contractility via nuclear factor $\kappa \mathrm{B}(\mathrm{NF}-\kappa \mathrm{B})$ in a rat bile duct ligation model of cirrhosis has been reported [53]. The NF- $\kappa \mathrm{B}$ proteins are a family of transcription factors that regulate cellular responses. In this particular study, the cardiomyocytes of cirrhotic animals showed reduced contractile response to isoproterenol, with increased myocardial levels of TNF- $\alpha$ and NF- $\kappa \mathrm{B}$. TNF- $\alpha$-mediated myocardial dysfunction in response to endotoxin stimulation is well documented [54]. NF- $\kappa \mathrm{B}$ inhibition resulted in significant reduction in NF- $\kappa \mathrm{B}$ activity and TNF- $\alpha$ expression, as well as restoration of contractile function [53], suggesting that TNF- $\alpha$-related myocardial dysfunction in cirrhosis is also NF- $\kappa \mathrm{B}$ dependent.

\section{Diastolic dysfunction}

The presence of diastolic dysfunction leads to abnormal left ventricular relaxation during diastole, usually owing to decreased dispensability of cardiac tissue, the result of either hypertrophy of cardiomyocytes or increased interstitial collagen deposition. Therefore, there is impedance to ventricular inflow, and the end-diastolic left ventricular pressure is elevated relative to the left ventricular end- 
diastolic volume. As early as 1958, Lunseth et al. [55] reported on the presence of myocardial thickening in an autopsy series of cirrhotic patients who did not have any history or pathological features of systemic hypertension, coronary artery disease, or valvular disease. Histological examination revealed cardiomyocyte hypertrophy, altered pigmentation, nuclear vacuolization, edema, and fibrosis [55]. There is no direct evidence from either human or animal studies that explore the pathogenesis of diastolic dysfunction in cirrhosis. Borrowing from the experience of studies in systemic hypertension, the diastolic dysfunction of cirrhosis is thought to be secondary to sodium retention, volume expansion, and activation of the various neurohormonal systems that are commonly observed in these patients.

In normotensive rats, increasing the sodium intake has been shown to increase their left ventricular weight by 20-25\% without increasing their resting blood pressure, cardiac filling pressure, or cardiac sympathetic activity [56-58], suggesting that excess sodium per se can induce myocardial hypertrophy independent of volume expansion. The hypertrophic response is proportional to the sodium contents of the diet [59]. It is thought that a high sodium diet increases cardiomyocyte sodium contents and enhances cytosolic kinetics, leading to cardiomyocyte hypertrophy [59]. In addition, sodium enhances the fibrogenic effects of aldosterone. When given with a high sodium diet, aldosterone has been shown to increase the gene expression of major isoforms of $\mathrm{Na}^{+} \mathrm{K}^{+}$ATPase, or the sodium pump, in various cell types $[60,61]$. The resultant higher cellular sodium content in fibroblasts can significantly increase their mitogenic potential, leading to increased fibrosis [61]. Alternatively, it has been suggested that high sodium intake stimulates the intracardiac production of various cytokines, including transforming growth factor (TGF)- $\beta$. TGF- $\beta$ in turn, acts in an autocrine or paracrine fashion to increase the production of endothelin 1 [62], which also has direct trophic effects on the myocardium [63]. Human studies have also reported a correlation between the sodium intake and left ventricular wall thickness [64].

Mechanical stretch such as volume overload activates the intracardiac renin-angiotensin system (RAS) and this can trigger the intracardiac production of angiotensin II (Ang II) [65]. Binding of Ang II to its angiotensin type 1 (AT1) receptors in the myocardium activates a cascade of intracellular events to promote cardiomyocyte hypertrophy. The process involves the alteration of the cytosolic calcium content to activate the protein kinase cascade to induce hypertrophy [66]. In addition, Ang II can stimulate fibroblast proliferation, leading to an increase in extracellular matrix production [66]. Thus, Ang II stimulation can cause both cardiomyocyte hypertrophy and an increased interstitium. Recent data suggest that a specific cardiac fibroblast-derived factor in turn augments the Ang IIinduced myocyte growth [67]. Other trophic hormones for cardiomyocytes that are present in abundance, especially in decompensated cirrhosis, are endothelin and norepinephrine, and both can cause cardiac hypertrophy even in the absence of stretch $[68,69]$.

The recent study assessing the role of NF- $\kappa \mathrm{B}$ in mediating systolic dysfunction in cirrhosis also showed an improvement of diastolic relaxation in cardiomyocytes when its inhibitors blocked NF- $\kappa$ B activity, with reduction in TNF- $\alpha$ expression [53]. This suggests that an inflammatory milieu, with increased TNF- $\alpha$ levels, may also be partly responsible for the diastolic dysfunction in cirrhosis, but the exact mechanism with which TNF- $\alpha$ affects diastolic dysfunction has not been elucidated.

\section{Electrophysiological abnormalities}

Electrophysiological abnormalities in cirrhosis are due to a combination of plasma membrane changes, $\beta$-adrenoceptor and postreceptor pathway defects, and a generalized ion channel dysfunction [14]. All of the aforementioned abnormalities in membrane fluidity and $\beta$-adrenergic signaling pathway in cirrhosis (under the "Systolic dysfunction" section) can lead to a delay in the electrical excitation and its mediation of the mechanical contraction, resulting in impaired electromechanical coupling.

Various ion channel defects in cirrhosis have now been associated with prolongation of the action potential of the cardiomyocytes, which results in extension of ventricular systole or a prolonged QT interval. In healthy individuals, the interior of the cardiomyocyte is electrically negative with respect to the exterior. With adrenergic stimulation, rapid depolarization occurs as a result of opening of sodium $\left(\mathrm{Na}^{+}\right)$channels, leading to a rapid influx of $\mathrm{Na}^{+}$ into cardiomyocytes. At a slightly higher voltage, the slow calcium $\left(\mathrm{Ca}^{2+}\right)$ channels open, allowing $\mathrm{Ca}^{2+}$ to enter the cardiomyocytes (Phase 0, Fig. 3). This initiates myocardial contraction. The $\mathrm{Na}^{+}$channels then close and $\mathrm{Na}^{+}$flux ceases (Phase 1, Fig. 3). Outward rectifier potassium $\left(\mathrm{K}^{+}\right)$ channels then open transiently, extruding $\mathrm{K}^{+}$while $\mathrm{Ca}^{2+}$ influx continues (Phase 2, Fig. 3). The length of the plateau phase of the action potential depends on a balance between the efflux of $\mathrm{K}^{+}$and the influx of $\mathrm{Ca}^{2+}$. The $\mathrm{Ca}^{2+}$ channels then close, whereas $\mathrm{K}^{+}$efflux continues through the delayed rectifier $\mathrm{K}^{+}$channels, and repolarization occurs (Phase 3, Fig. 3). Finally, the $\mathrm{K}^{+}$channels close, and $\mathrm{Na}^{+}$ and $\mathrm{Ca}^{2+}$ are being actively pumped out to return to the resting state (Phase 4, Fig. 3). Impaired function of $\mathrm{K}^{+}$ channels in animal models of cirrhosis has been reported [70], thereby reducing $\mathrm{K}^{+}$extrusion and prolonging the action potential or the QT interval. 


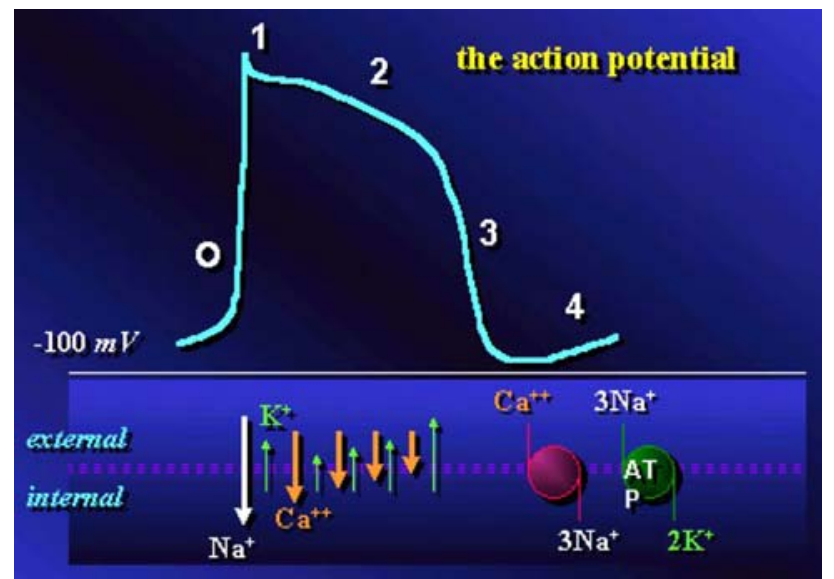

Fig. 3 The different phases of the action potential. Abbreviations: ATP, adenosine triphosphate; $\mathrm{Ca}^{2+}$, calcium; $\mathrm{K}^{+}$, potassium; $\mathrm{Na}^{+}$, sodium

Finally, various "toxins" that are commonly found in excess amounts in cirrhosis may also contribute to the electromechanical abnormalities in cirrhosis. For example, elevated endotoxin levels, especially in cirrhosis complicated by bacterial infections [71], can reduce the inward $\mathrm{Ca}^{2+}$ current, thereby widening the QRS complex as it has been shown in experimental settings [72]. Endothelin, apart from inducing myocardial hypertrophy, is also capable of inducing changes in ion currents in cardiomyocyte preparations in vitro [73]. Therefore, it is feasible that the elevated endothelin levels in cirrhosis [74] may also contribute to the electrophysiological changes in these patients. Increased bile acid levels in patients with biliary cirrhosis can affect membrane fluidity of myocytes, leading to the alteration of function of $\beta$-adrenoceptors, $\mathrm{G}$ protein, and ion channels [75] in patients with cholestasis.

\section{Clinical presentations and consequences of cirrhotic cardiomyopathy}

Systolic function in cirrhosis is often normal at rest, and in advanced cirrhosis, it is even supernormal, with tachycardia, high ejection fraction, and increased cardiac output, the so-called hyperdynamic circulation [76]. However, systolic dysfunction is often unmasked when these patients are placed under physical $[6,77]$ or pharmacological stress [78]. Inability to perform physical activities is rarely an issue with cirrhotic patients, especially those with ascites, because their generalized wasting means their systolic function is not often challenged with physical stress. But in situations where a higher cardiac output is required such as the development of bacterial infections in cirrhosis, systolic incompetence becomes manifested. Indeed, in cirrhotic patients with spontaneous bacterial peritonitis, patients who went on to develop hepatorenal syndrome (HRS) had a reduced cardiac output at infection diagnosis, which decreased further at infection resolution [79], suggesting that the inability to mount a sufficient cardiac output in the presence of bacterial infection has contributed to a reduced renal perfusion pressure, thereby contributing to the development of HRS. In fact, the same authors reported that those cirrhotic patients destined to develop HRS had lower cardiac output even prior to the onset of HRS [80], with lower mean arterial pressure and higher neurohormonal levels, suggesting that an inadequate cardiac output in the presence of systemic arterial vasodilatation predisposes these cirrhotic patients to further complications. In the case of bacterial infections, the presence of negative inotropic cytokines such as TNF- $\alpha$ and interleukin- $1 \beta$ further lowers cardiac systolic function, thereby further reducing cardiac output, leading to the development of HRS.

Systolic dysfunction may also contribute to sodium retention in cirrhosis. Decrease in cardiac contractile function is consistently associated with sympathetic activation, both in early and advanced cirrhosis [7]. Increased baroreceptor- and volume-receptor-mediated sympathetic firing with subsequent neuronal release of norepinephrine is a physiological response to increase cardiac contractility, thereby returning cardiac performance to an adequate level but at the cost of substantial encroachment on the FrankStarling reserve [81]. But this sympathetic overdrive can also directly stimulate renal sodium and water retention and indirectly activate the renal RAS, which enhances the renal sodium and water retention. Evidence suggesting systolic dysfunction being implicated in renal sodium retention was shown in a study that demonstrated an exaggerated inverse single-beat pressure/volume relationship (an index of contractile dysfunction) in preascitic cirrhotic patients when they were given a high sodium diet, with renal sodium retention. Ascitic cirrhotic patients with their avid sodium retention also demonstrated an inverse single-beat systolic pressure/volume relationship, which was worse compared with that of the preascitic patients [9]. Further studies are needed to confirm the role of cirrhotic cardiomyopathy in the pathogenesis of sodium retention in cirrhosis.

Diastolic dysfunction is most likely to lead to clinical problems when there is a sudden volume load because the stiff and hypertrophic left ventricle cannot relax to accommodate the excess volume. This is most evident during the insertion of a TIPS shunt or in the immediate post-liver transplant period. Indeed, cardiac complications have been reported following TIPS insertion [82, 83]. Huonker and colleagues [84] reported almost doubling of pulmonary wedge pressure and total pulmonary vascular resistance $90 \mathrm{~min}$ after a successful TIPS insertion, 
reflecting diastolic dysfunction. Cazzaniga and colleagues [85] observed that an E/A ratio of 1 or lower, as well as index of diastolic dysfunction, at 1 month post-TIPS insertion was associated with an increased risk for mortality during follow-up. Rabie and colleagues [86] reported that the E/A ratio of 1 or lower observed pre-TIPS would be a better predictor of mortality after TIPS, especially deaths from renal failure. In the same study, the presence of the E/A ratio of 1 or lower pre-TIPS was also associated with a slower rate of ascites clearance. The authors postulated that patients with diastolic dysfunction were unable to increase their preload adequately after TIPS and therefore unable to mount an adequate increase in their cardiac output to fill the ever-increasing vascular capacitance due to significant vasodilatation after TIPS. Therefore, the relative underfilling of the effective arterial circulation persists after TIPS, with resultant slow clearance of the ascites. There is some evidence (personal data) that the myocardial thickening continues to increase in the postTIPS period, possibly as an adaptation to the continued volume overload in the post-TIPS period. The corollary from this observation is that careful cardiac investigations are advisable prior to the TIPS insertion.

In the immediate posttransplant period, pulmonary edema as a result of left ventricular failure has been reported in as high as 56\% of transplant recipients [87], although in most cases, the pulmonary edema resolves with medical therapy. Sampathkumar and colleagues [88] reported severe myocardial dysfunction occurring in $1 \%$ of patients after liver transplantation. During reperfusion, the return of a significant volume to the heart can unmask any diastolic dysfunction. This, when coupled with various metabolic abnormalities such as electrolyte imbalance, surgical stress, and graft production of cardiac-depressant cytokines such as TNF- $\alpha$, may be the explanation for the high prevalence of cardiac morbidity in the posttransplant period despite no evidence of cardiac dysfunction on 2-dimensional and dobutamine stress echocardiography before surgery [87]. Diastolic dysfunction becomes more pronounced in the first 3 months posttransplant, possibly owing to increased ventricular hypertrophy [89]. When followed long-term for more than 1 year, there is complete reversal of cardiac changes in the posttransplant patients [90].

QT prolongation, a common electrophysiological abnormality in cirrhosis [12], also worsens after the TIPS insertion, especially in the first 3 months post-TIPS [91]. This is thought to be due to the translocation of cardiotoxic substances from the splanchnic to the systemic circulation through the TIPS shunt, affecting ventricular repolarization, hence prolonging the QT interval. This may also contribute to the increased risks for cardiac complications post-TIPS [85].

\section{Treatment of cirrhotic cardiomyopathy}

As most cases of cirrhotic cardiomyopathy are subclinical, and symptoms become overt only when cardiac function is stressed, there has been very little interest in treating cirrhotic cardiomyopathy, especially at the asymptomatic stage. Once cardiac failure becomes evident following some form of stress, management should follow similar guidelines as in noncirrhotic patients, although cardiac afterload reduction will not be well tolerated in patients with advanced cirrhosis who are significantly vasodilated. To date, there are no clinical studies on the management of cirrhotic cardiomyopathy. However, as cirrhotic cardiomyopathy is increasingly recognized as a cause of potential morbidity and mortality in the natural history of cirrhosis, there have been some attempts at evaluating treatment options.

Because $\beta$-adrenergic blockade can lower portal pressure and potentially reduce the degree of shunting of cardiotoxins from the splanchnic to the systemic circulation, Henriksen and colleagues [92] reported that the administration of a single dose of propranolol improved the QT interval in cirrhosis. Zambruni and colleagues [93] assessed the effects of chronic administration of a nonselective $\beta$-blocker on QT intervals in a cohort of cirrhotic patients with varying degrees of decompensation. This was effective in reducing the QT interval only in patients with a baseline prolonged QT interval, but it lengthened the QT interval in those with normal baseline QT intervals. Furthermore, there was no correlation between the change in QT interval with $\beta$-blockade and the reduction in portal pressure, suggesting that portal hypertension and shunting were not involved in QT prolongation. The authors suggested that patients with prolonged QT intervals at baseline mostly likely had $\mathrm{K}^{+}$channel dysfunction, and as such were most sensitive to the lengthening effects of sympathetic overdrive and hence derived the most benefits from $\beta$-blockade. Therefore, until the effects of chronic $\beta$-adrenergic blockade are fully elucidated, it cannot be recommended as a treatment of cirrhotic cardiomyopathy.

Pozzi and colleagues [94] recently demonstrated that the use of an aldosterone antagonist, k-canrenoate, for 6 months can reduce the parietal wall thickness of the left ventricle even in patients at an early stage of cirrhosis, the so-called preascitic cirrhosis. The rationale for using an aldosterone antagonist was to counteract the fibrotic effects of aldosterone and reduce the circulatory volume load, and this has the potential of reducing myocardial hypertrophy and stiffness, thereby improving diastolic dysfunction in cirrhosis. The use of low-dose spironolactone in the treatment of heart failure [95] certainly lends credence to this hypothesis. However, this particular study showed that despite a significant reduction in left ventricular wall 
thickness and left ventricular end-diastolic volume, there was no significant change in diastolic function. Potential relevant studies to further delineate the role of aldosterone antagonism in the management of cirrhotic cardiomyopathy include a longer period of administration, or the use of different doses, or inclusion of cirrhotic patients at a more advanced stage of cirrhosis.

Liver transplantation can completely reverse the changes of cirrhotic cardiomyopathy and therefore can potentially be one of the treatment options for this condition. However, in the era of organ shortage, cirrhotic cardiomyopathy is unlikely to be the sole indication for liver transplantation. Future strategies will include formulation of new treatment options based on extrapolation of animal study findings, such as the development of antagonists to TNF- $\alpha$ and NF- $\kappa \mathrm{B}$ as treatments of systolic dysfunction, or the use of the combination of $\beta$-blockade with aldosterone antagonist, or the use of Ang II receptor antagonist as treatment of diastolic dysfunction. The removal of "cardiotoxins" using albumin is also a possibility.

\section{Conclusion}

Since the term "cirrhotic cardiomyopathy" was coined by Lee almost 2 decades ago (15), investigators have made significant advances in the understanding of the pathogenetic mechanisms, clinical manifestations, and the potential complications of this condition. However, there is still a great deal about cirrhotic cardiomyopathy that is unknown. We do not yet have a single diagnostic test that can identify patients with cirrhotic cardiomyopathy. Treatment options are beginning to be evaluated, but prophylaxis is not yet a reality. Recognition of cirrhotic cardiomyopathy will depend on a high level of awareness for this syndrome and potentially will help better manage patients with cirrhosis. For example, the understanding of cardiac changes in the post-TIPS period will lead to better selection of patients for the TIPS procedure. To date, the knowledge gained from the various animal studies has provided much insight into this condition. The future will be in the development of effective treatment strategies so as to improve the outcome of these patients.

\section{References}

1. Kowalski HJ, Abelmann WH. The cardiac output at rest in Laennec cirrhosis. J Clin Invest 1953;32:1025-1033

2. Rayes N, Bechstein WO, Keck H, Blumhardt G, Lohmann R, Neuhaus P. Causes of death after liver transplantation: an analysis of 41 cases in 382 patients. Zentralblatt Chir 1995;120:435-438
3. Lebrec D, Giuily N, Hadenque A, Vilgrain V, Moreau R, Poynard $\mathrm{T}$, et al. Transjugular intrahepatic portosystemic shunt: comparison with paracentesis in patients with cirrhosis and refractory ascites: a randomized trial. J Hepatology 1996;25:135-144

4. Franco D, Vons C, Traynor O, de Smadja C. Should portocaval shunt be reconsidered in the treatment of intractable ascites in cirrhosis? Arch Surg 1988;123:987-991

5. Laffi G, Barletta G, La Villa G, Del Bene R, Riccardi D, Ticali P, et al. Altered cardiovascular responsiveness to active tilting in nonalcoholic cirrhosis. Gastroenterology 1997;113:891-898

6. Wong F, Girgrah N, Graba J, Allidina Y, Liu P, Blendis L. The effect of cirrhotic cardiomyopathy on the cardiac response to exercise in cirrhosis. Gut 2001;49:268-275

7. Bernardi M, Rubboli A, Trevisani F, Cancellieri C, Ligabue A, Baraldini $\mathrm{M}$, et al. Reduced cardiovascular responsiveness to exercise-induced sympathoadrenergic stimulation in patients with cirrhosis. J Hepatol 1991;12:207-216

8. Moreau R, Hadengue A, Soupison T, Mechin G, Assous M, Roche-Sicot J, et al. Abnormal pressor response to vasopressin in patients with cirrhosis: evidence for impaired buffering mechanism. Hepatology 1990;12:7-12

9. Wong F, Liu P, Lilly L, Bomzon A, Blendis L. The role of cardiac structural and functional abnormalities in the pathogenesis of hyperdynamic circulation and renal sodium retention in cirrhosis. Clin Sci 1999;97:259-267

10. Pozzi M, Carugo S, Boari G, Pecci V, de Ceglia S, Maggiolini S, et al. Functional and structural cardiac abnormalities in cirrhotic patients with and without ascites. Hepatology 1997;26:1131-1137

11. Finucci G, Desideri A, Sacerdoti D, Bolognesi M, Merkel C, Angeli $\mathrm{P}$, et al. Left ventricular diastolic dysfunction in liver cirrhosis. Scan J Gastroenterol 1996;31:279-284

12. Bernardi M, Calandra S, Colantoni A, Trevisani F, Raimondo ML, Sica G, et al. QT interval prolongation in cirrhosis: prevalence, relationship with severity, and etiology of the disease and possible pathogenetic factors. Hepatology 1998;27:28-34

13. Kosar F, Ates F, Sahin I, Karincaoglu M, Yildirim B. QT interval analysis in patients with chronic liver disease: a prospective study. Angiology 2007;58:218-224

14. Zambruni A, Trevisani F, Caraceni P, Bernardi M. Cardiac electrophysiological abnormalities in patients with cirrhosis. J Hepatol 2006;44:994-1002

15. Lee SS. Cardiac abnormalities in liver cirrhosis. West J Med 1989;151:530-539

16. Ingles AC, Hernandez I, Garcia-Estan J, Quesada T, Carbonell LF. Limited cardiac preload reserve in conscious cirrhotic rats. Am J Physiol 1991;260:H1912-H1917

17. Caramelo C, Fernandez-Munoz D, Santos JC, Blanchart A, Rodriguez-Puyol D, López-Novoa JM, et al. Effect of volume expansion on hemodynamics, capillary permeability and renal function in conscious, cirrhotic rats. Hepatology 1986;6:129-134

18. Castro A, Jimenez W, Claria J, Ros J, Martinez JM, Bosch M, et al. Impaired responsiveness to angiotensin-II in experimental cirrhosis: role of nitric oxide. Hepatology 1993;18:367-372

19. Polio J, Sieber CC, Lerner E, Groszmann RJ. Cardiovascular hyporesponsiveness to norepinephrine, propranolol and nitroglycerin in portal-hypertensive and aged rats. Hepatology 1993;18:128-136

20. Weissler AM. Current concepts in cardiology: systolic time intervals. N Engl J Med 1977;296:321-324

21. Grose RD, Nolan J, Dillon JF, Errington M, Hannan WJ, Bouchier IAD, et al. Exercise-induced left ventricular dysfunction in alcoholic and non-alcoholic cirrhosis. J Hepatology 1995;22:326332

22. Sagawa K, Suga H, Shoukas A, Bakalar KM. End-systolic pressure/volume ratio: a new index of ventricular contractility. Am J Cardiol 1997;40:748-753 
23. Lunzer MR, Newman SP, Bernard AG, Manghani KK, Sherlock SP, Ginsburg J. Impaired cardiovascular responsiveness in liver disease. Lancet 1975;2:382-385

24. Decaux G, Cauchie P, Soupart A, Kruger M, Delwiche F. Role of vagal neuropathy in the hyponatraemia of alcoholic cirrhosis. $\mathrm{Br}$ Med J 1986;293:1534-1536

25. Henriksen JH, Fuglsang S, Bendtsen F, Christensen E, Moller S. Dyssynchronous electrical and mechanical systole in patients with cirrhosis. J Hepatol 2002;36:513-520

26. Henriksen JH, Gotze JP, Fuglsang S, Christensen E, Bendtsen F, Moller S. Increased circulating pro-brain natriuretic peptide (proBNP) and brain natriuretic peptide (BNP) in patients with cirrhosis: relation to cardiovascular dysfunction and severity of disease. Gut 2003;52:1511-1517

27. La Villa G, Romanelli RG, Casini Raggi V, Tosti-Guerra C, De Feo ML, Marra F, et al. Plasma levels of brain natriuretic peptide in patients with cirrhosis. Hepatology 1992;16:156-161

28. Wong F, Siu S, Liu P, Blendis L. Brain natriuretic peptide, is it a predictor of cardiomyopathy in cirrhosis? Clin Sci 2001;101:651-657

29. Iwao T, Oho K, Nakano R, Sakai T, Sato M, Miyamoto Y, et al. High plasma cardiac natriuretic peptides associated with enhanced cyclic guanosine monophosphate production in preascitic cirrhosis. J Hepatol 2000;32:426-433

30. Yildiz R, Yildirim B, Karincaoglu M, Harputluoglu M, Hilmioglu F. Brain natriuretic peptide and severity of disease in non-alcoholic cirrhotic patients. J Gastroenterol Hepatol 2005;20:1115-1120

31. Bodor GS, Porter S, Landt Y, Ladenson JH. Development of monoclonal antibodies for an assay of cardiac troponin-I and preliminary results in suspected cases of myocardial infarction. Clin Chem 1992;38:2203-2214

32. Pateron D, Beyne P, Laperche T, Logeard D, Lefilliatre P, Sogni $\mathrm{P}$, et al. Elevated circulating cardiac troponin I in patients with cirrhosis. Hepatology 1999;29:640-643

33. Parkes DG. Cardiovascular actions of adrenomedullin in conscious sheep. Am J Physiol 1995;268:H2574-H2578

34. Ikenouchi H, Kangawa K, Matsuo H, Hirata Y. Negative inotropic effects of adrenomedullin in isolated adult rabbit cardiac ventricular myocytes. Circulation 1997;95:2318-2324

35. Szokodi I, Kinnunen P, Tavi P, Weckstrom M, Toth M, Zruskoaho $\mathrm{H}$. Evidence of adrenomedullin, a new inotropic peptide. Circulation 1998;97:1062-1070

36. Guevara M, Gines P, Jimenez W, Sort P, Fernandez-Esparrach G, Escorsell A, et al. Increased adrenomedullin levels in cirrhosis: relationship with hemodynamic abnormalities and vasoconstrictor systems. Gastroenterology 1998;114:336-343

37. Genesca J, Gonzalez A, Catalan R, Segura R, Martinez M, Esteban R, et al. Adrenomedullin, a vasodilator peptide implicated in hemodynamic alterations of liver cirrhosis. Relationship to nitric oxide. Dig Dis Sci 1999;44:372-376

38. Jougasaki M, Wei CM, McKinley LJ, Burnett JCJ. Elevation of circulating and ventricular adrenomedullin in human congestive heart failure. Circulation 1995;92:286-289

39. Kobayashi K, Kitamura K, Etoh T, Nagatomo Y, Takenaga M, Ishikawa $\mathrm{T}$, et al. Increased plasma adrenomedullin levels in chronic congestive heart failure. Am Heart J 1996;131:994-998

40. Hirano S, Imamura T, Matsuo T, Ishiyama Y, Kato J, Kitamura $\mathrm{K}$, et al. Differential responses of circulating and tissue adrenomedullin and gene expression to volume overload. J Card Fail 2000;6:120-129

41. Pan CS, Jin SJ, Cao CQ, Zhao J, Zhang J, Wang X, et al. The myocardial response to adrenomedullin involves increased cAMP generation as well as augmented Akt phosphorylation. Peptides 2007;28:900-909

42. Ishimitsu T, Ono H, Minami J, Matsuoka H. Pathophysiologic and therapeutic implications of adrenomedullin in cardiovascular disorders. Pharmacol Ther 2006;111:909-927
43. Møller S, Henriksen JH. Cardiovascular complications of cirrhosis. Gut 2008;57:268-278

44. Xiao RP, Cheng H, Zhou YY, Kuschel M, Lakatta EG. Recent advances in cardiac beta-adrenergic signal transduction. Circ Res 1999;85:1092-1100

45. Alqahtani SA, Fouad TR, Lee SS. Cirrhotic cardiomyopathy. Sem Liver Dis 2008;28:59-69

46. Ma Z, Lee SS, Meddings JB. Effects of altered cardiac membrane fluidity on beta-adrenergic receptor signalling in rats with cirrhotic cardiomyopathy. J Hepatol 1997;26:904-912

47. Ma Z, Miyamoto A, Lee SS. Role of altered beta-adrenoceptor signal transduction in the pathogenesis of cirrhotic cardiomyopathy in rats. Gastroenterology 1996;110:1191-1198

48. Caraceni P, Domenicali M, Bernardi M. The endocannabinoid system and liver diseases. J Neuroendocrinol 2008;20(Suppl 1):47-52

49. Gaskari SE, Liu H, Moezi L, Li Y, Baik SK, Lee SS. Role of endocannabinoids in the pathogenesis of cirrhotic cardiomyopathy in bile duct ligated rats. Br J Pharmacol 2005;146:315-323

50. Batkai S, Mukhopadhyay P, Harvey-White J, Kekrid R, Pacher P, Kunos G. Endocannabinoids acting at CB1 receptors mediate the cardiac contractile dysfunction in vivo in cirrhotic rats. Am J Physiol Heart Circ Physiol 2007;293:H1689-H1695

51. Liu H, Ma Z, Lee SS. Contribution of nitric oxide to the pathogenesis of cirrhotic cardiomyopathy in bile duct-ligated rats. Gastroenterology 2000;118:937-944

52. Liu H, Song D, Lee SS. Role of heme oxygenase-carbon monoxide pathway in pathogenesis of cirrhotic cardiomyopathy in the rat. Am J Physiol Gastrointest Liver Physiol 2001;280:G68-G74

53. Liu H, Lee SS. Nuclear factor-kappaB inhibition improves myocardial contractility in rats with cirrhotic cardiomyopathy. Liver Int 2008;28:640-648

54. Piper RD. Myocardial dysfunction in sepsis. Clin Exp Pharmacol Physiol 1998;25:951-954

55. Lunseth JH, Olmstead EG, Abboud F. A study of heart disease in one hundred eight hospitalized patients dying with portal cirrhosis. Arch Intern Med 1958;102:405-413

56. Fields NG, Yuan B, Leenen FHH. NaCl-induced cardiac hypertrophy: cardiac sympathetic activity versus volume load. Circ Res 1991;68:745-755

57. Kihara M, Utagawa N, Mano Y, Horie R, Yamori Y. Biochemical aspects of salt-induced, pressure-independent left ventricular hypertrophy in rats. Heart Vessel 1985;1:212-215

58. Meggs LG, Ben-Ari J, Gammon D, Goodman AI. Myocardial hypertrophy: the effects of sodium and the role of sympathetic nervous activity. Am J Hypertens 1988;1:1-11

59. Leenen FHH, Yuan B. Dietary-sodium-induced cardiac remodeling in spontaneously hypertensive rat versus Wistar-Kyoto rat. J Hypertens 1998;16:885-892

60. Yoshimoto T, Hirata Y. Aldosterone as a cardiovascular risk hormone. Endocr J 2007;54:359-370

61. Weber KT, Sun Y, Tyagi SC, Cleutjens JP. Collagen network of the myocardium: function, structural remodeling and regulatory mechanisms. J Mol Cell Cardiol 1994;26:279-292

62. van Wamel AJ, Ruwhof C, van der Valk-Kokshoom LE, Schrier PI, van der Laarse A. The role of angiotensin II endothelin-1 and transforming growth factor-beta as autocrine/paracrine mediators of stretch-induced cardiomyocyte hypertrophy. Mol Cell Biochem 2001;218:113-124

63. Yamazaki T, Komuro I, Kudoh S, Zou Y, Shiojima I, Hiroi Y, et al. Endothelin-1 is involved in mechanical stress-induced cardiomyocyte hypertrophy. J Biol Chem 1996;271:3221-3228

64. Schmieder RE. Salt intake is related to the process of myocardial hypertrophy in essential hypertension. JAMA 1989;262:1187-1188

65. Raizada V, Skipper B, Luo W, Griffith J. Intracardiac and intrarenal renin-angiotensin systems: mechanisms of cardiovascular and renal effects. J Investig Med 2007;55:341-359 
66. Dostal DE, Hunt RA, Kule CE, Bhat GJ, Karoor V, McWhinney $\mathrm{CD}$, et al. Molecular mechanisms of angiotensin II in modulating cardiac function: intracardiac effects and signal transduction pathways. J Mol Cell Cardiol 1997;29:2893-2902

67. Booz GW, Dostal DE, Baker KM. Paracrine actions of cardiac fibroblasts on cardiomyocytes: implications for the cardiac reninangiotensin system. Am J Cardiol 1999;83:44H-47H

68. Zierhut W, Zimmer HG. Significance of myocardial $\alpha$ - and $\beta$-adrenoreceptors in catecholamine induced cardiac hypertrophy. Circ Res 1989;65:1417-1425

69. Dostal DE, Baker KM. Angiotensin and endothelin: messengers that couple ventricular stretch to the $\mathrm{Na}^{+} / \mathrm{H}^{+}$exchanger and cardiac hypertrophy. Circ Res 1998;83:870-873

70. Ward CA, Ma Z, Lee SS, Giles WR. Potassium currents in atrial and ventricular myocytes from a rat model of cirrhosis. Am J Physiol 1997;273:G537-G544

71. Lin RS, Lee FY, Lee SD, Tsai YT, Lin HC, Lu RH, et al. Endotoxemia in patients with chronic liver diseases: relationship to severity of liver diseases, presence of esophageal varices, and hyperdynamic circulation. J Hepatol 1995;22:165-172

72. Zhong J, Hwang TC, Adams HR, Rubin LJ. Reduced L-type calcium current in ventricular myocytes from endotoxemic guinea pigs. Am J Physiol 1997;273:H2312-H2324

73. Magyar J, Iost N, Kortvely A, Banyasz T, Virag L, Szigligeti P, et al. Effects of endothelin-1 on calcium and potassium currents in undiseased human ventricular myocytes. Pflugers Arch 2000;441: 144-149

74. Kuddus RH, Nalesnik MA, Subbotin VM, Rao AS, Gandhi CR. Enhanced synthesis and reduced metabolism of endothelin-1 (ET-1) by hepatocytes - an important mechanism of increased endogenous levels of ET-1 in liver cirrhosis. J Hepatol 2000;33: 725-732

75. Gazawi H, Ljubuncic P, Cogan U, Hochgraff E, Ben-Shachar D, Bomzon A. The effects of bile acids on beta-adrenoceptors, fluidity, and the extent of lipid peroxidation in rat cardiac membranes. Biochem Pharmacol 2000;59:1623-1628

76. Gould L, Shariff M, Zahir M, Di Lieto M. Cardiac hemodynamics in alcoholic patients with chronic liver disease and a presystolic gallop. J Clin Invest 1969;48:860-868

77. Kelbaek H, Eriksen J, Brynjolf I, Raboel A, Lund JO, Munck O, et al. Cardiac performance in patients with asymptomatic alcoholic cirrhosis of the liver. Am J Cardiol 1984;54:852-855

78. Limas CJ, Guiha NH, Lekagul O, Cohn JN. Impaired left ventricular function in alcoholic cirrhosis with ascites. Ineffectiveness of ouabain. Circulation 1974;49:754-760

79. Ruiz-del-Arbol L, Urman J, Fernández J, González M, Navasa M, Monescillo A, et al. Systemic, renal, and hepatic hemodynamic derangement in cirrhotic patients with spontaneous bacterial peritonitis. Hepatology 2003;38:1210-1218

80. Ruiz-del-Arbol L, Monescillo A, Arocena C, Valer P, Ginès P, Moreira V, et al. Circulatory function and hepatorenal syndrome in cirrhosis. Hepatology 2005;42:439-447

81. Ferguson DW, Berg WJ, Roach PJ, Oren RM, Mark AL. Effects of heart failure on baroreflex control of sympathetic neural activity. Am J Cardiol 1992;69:523-531
82. Braverman AC, Steiner MA, Picus D, White H. High-output congestive heart failure following transjugular intrahepatic portal-systemic shunting. Chest 1995;107:1467-1469

83. Ginès P, Uriz J, Calahorra B, Garcia-Tsao G, Kamath PS, Del Arbol LR, et al. Transjugular intrahepatic portosystemic shunting versus paracentesis plus albumin for refractory ascites in cirrhosis. Gastroenterology 2002;123:1839-1847

84. Huonker M, Schumacher YO, Ochs A, Sorichter S, Keul J, Rössle M. Cardiac function and haemodynamics in alcoholic cirrhosis and effects of the transjugular intrahepatic portosystemic stent shunt. Gut 1999;44:743-748

85. Cazzaniga M, Salerno F, Pagnozzi G, Dionigi E, Visentin S, Cirello I, et al. Diastolic dysfunction is associated with poor survival in patients with cirrhosis with transjugular intrahepatic portosystemic shunt. Gut 2007;56:869-875

86. Rabie R, Cazzaniga M, Salerno F, Wong F. The effect of cirrhotic cardiomyopathy on the post-TIPS outcome of patients treated for complications of portal hypertension. [abstract]. Hepatology 2006;44(Suppl 1):444A

87. Donovan CL, Marcovitz PA, Punch JD, Bach DS, Brown KA, Lucey MR, et al. Two-dimensional and dobutamine stress echocardiography in the preoperative assessment of patients with end-stage liver disease prior to orthotopic liver transplantation. Transplantation 1996;61:1180-1188

88. Sampathkumar P, Lerman A, Kim BY, Narr BJ, Poterucha JJ, Torsher LC, et al. Post-liver transplantation myocardial dysfunction. Liver Transpl Surg 1998;4:399-403

89. Therapondos G, Flapan AD, Plevris JN, Hayes PC. Cardiac morbidity and mortality related to orthotopic liver transplantation. Liver Transpl 2004;10:1441-1453

90. Torregrosa M, Aguadé S, Dos L, Segura R, Gónzalez A, Evangelista A, et al. Cardiac alterations in cirrhosis: reversibility after liver transplantation. J Hepatol 2005;42:68-74

91. Trevisani F, Merli M, Savelli F, Valeriano V, Zambruni A, Riggio O, et al. QT interval in patients with non-cirrhotic portal hypertension and in cirrhotic patients treated with transjugular intrahepatic porto-systemic shunt. J Hepatol 2003;38:461-467

92. Henriksen JH, Bendtsen F, Hansen EF, Møller S. Acute nonselective beta-adrenergic blockade reduces prolonged frequencyadjusted Q-T interval (QTc) in patients with cirrhosis. J Hepatol 2004;40:239-246

93. Zambruni A, Trevisani F, Di Micoli A, Savelli F, Berzigotti A, Bracci E, et al. Effect of chronic beta-blockade on QT interval in patients with liver cirrhosis. J Hepatol 2008;48:415-421

94. Pozzi M, Grassi G, Ratti L, Favini G, Dell'Oro R, Redaelli E, et al. Cardiac, neuroadrenergic, and portal hemodynamic effects of prolonged aldosterone blockade in postviral child A cirrhosis. Am J Gastroenterol 2005;100:1110-1116

95. Pitt B, Zannad F, Remme WJ, Cody R, Castaigne A, Perez A, et al. The effect of spironolactone on morbidity and mortality in patients with severe heart failure. Randomized Aldactone Evaluation Study Investigators. N Engl J Med 1999;341:709-717 